\title{
Câmara dos Deputados: democracia e igualdade de oportunidades entre mulheres e homens?
}

\author{
Amanda Zauli ${ }^{1}$, Cláudio Vaz Torres ${ }^{2}$ e Ana Lúcia Galinkin ${ }^{3}$ \\ Departamento de Psicologia Social, do Trabalho e das Organizações \\ da Universidade de Brasília (Brasília, DF)
}

Esta pesquisa analisou as oportunidades das mulheres em termos de igualdade na ocupação de cargos de alta chefia na Câmara dos Deputados. A pesquisa de campo foi realizada entre novembro de 2005 e janeiro de 2006 e a amostra abrangeu 1.320 participantes. A Escala de Percepção de Igualdade de Oportunidades entre Mulheres e Homens foi aplicada para analisar a atitude dos servidores quanto a possibilidades e limites de ascensão da mulher na estrutura de cargos da organização. A escala constava de 34 itens, com respostas tipo Likert, e 6 itens sobre dados demográficos. A coleta de dados foi feita pela rede interna de computadores da Câmara dos Deputados, através de email enviado aos 3.597 servidores do quadro efetivo. Os dados foram submetidos à análise dos componentes principais (ACP), rotação promax, com resultados meritórios ( $\mathrm{KMO}=86,0$; Bartlett: 14894,879), para 4 fatores. Observaram-se diferenças entre mulheres e homens quanto aos escores obtidos. As oportunidades de ocupar cargo de alta chefia são menores para elas do que para eles. Há mais gerentes do sexo masculino, e os servidores, especialmente as mulheres que não ocupam posto de chefia, percebem que não há igualdade de oportunidades entre funcionários de ambos os sexos.

Palavras-chave: Diversidade, Mulheres, Igualdade, Ascensão na carreira.

House of Representatives: democracy and equal opportunities between women and men?

This research analyzed women's opportunities in terms of equality in the occupation of high leadership positions in the Brazilian House of Representatives. The field research was carried out from November 2005 to January 2006 and the survey comprised 1,320 respondents. The Perception Scale of Equal Opportunities Between Women and Men was applied to analyze the attitude of public servants with regard to women's ascension possibilities and limitations within the position structure of the organization. The scale consisted of 34 items, with Likert-style responses, and 6 items on demographic data. Data collection was carried out using the internal computer network of the House of Representatives, through an e-mail sent to the 3,597 effective public servants. Data underwent principal component analysis (PCA), promax rotation, with meritorious results (KMO $=86.0$; Bartlett:14894.879), to 4 factors. Differences between men and women were observed with regard to the scores obtained. The opportunities of occupying a high leadership position are smaller for women than men. There are more male managers, and the public servants, especially women who don't occupy chief positions, notice that there're no equal opportunities between employees of both sexes.

Keywords: Diversity, Women, Equality, Career ascension.

\section{Introdução}

$\mathrm{D}$ e acordo com o Perfil social, racial e de gênero das 500 maiores empresas do Brasil e suas ações afirmativas: pesquisa 2010, do Instituto Ethos (2010), dentre 1.506 ocupantes do quadro executivo das 500 maiores empresas brasileiras apenas $13,7 \%$ eram mulheres. Comparando-se esse resultado com o de 2005, época em que essa pesquisa foi realizada e $10,6 \%$ das mulheres empregadas ocupavam cargos de alta chefia, verifica-se um aumento de

1 Doutora em Psicologia Social, do Trabalho e das Organizações pela Universidade de Brasília (UnB) e supervisora de redação final da Câmara dos Deputados.

2 Doutor em Psicologia, professor do Programa de Pós-Graduação em Psicologia Social, do Trabalho e das Organizações da UnB. Bolsista Produtividade do CNPq.

3 Psicóloga, doutora em Sociologia, professora do Programa de Pós-Graduação em Psicologia Social, do Trabalho e das Organizações da UnB. 
3,1\% em cinco anos. Quanto mais alto é o nível hierárquico, menor continua sendo o acesso das mulheres. Segundo dados da Pesquisa Nacional por Amostra de Domicílio (PNAD/IBGE) e da Relação Anual de Informações Sociais (RAIS/MTE), ambas de 2004, "somente 14\% dos cargos de comando (gerência ou direção) são ocupados por mulheres” (Coelho, 2006, p. 143).

De acordo com A new look through the glass ceiling: where are the women (U. S. General Accounting Office, 2002), realizada em 2000, a maioria das gerentes mulheres ganhava salários menores do que em 1995. Segundo o estudo, realizado em dez indústrias, públicas e privadas, isso ocorre porque as mulheres continuavam a escolher ocupações e organizações em que tivessem maior flexibilidade de horário, para conciliar o trabalho e as tarefas domésticas, o que aumentava a segregação ocupacional. Os dados também mostraram que as mulheres ocupavam posições que exigiam menor nível educacional e recebiam salários menores.

O fenômeno da segmentação ocupacional é conhecido na literatura internacional como glass ceiling (teto de vidro), barreiras não explícitas, artificiais e invisíveis, criadas por preconceitos atitudinais e organizacionais que impedem o acesso das mulheres aos altos escalões organizacionais (Wirth, 2001; Coelho, 2006). Madalozzo (2011, p. 128), entretanto, esclarece:

A denominação de teto de vidro se deve ao fato de que a promoção interna é responsabilidade dos gestores da empresa, e os critérios para tal não são necessariamente públicos, nem mesmo para os membros internos da empresa, representando uma barreira intransponível e invisível, mas perceptível na análise de progressão na carreira.

\section{Fontenele-Mourão e Galinkin (2008, p. 91) comentam que:}

Apesar dos avanços em ocupações mais qualificadas e em nichos considerados masculinos, as áreas mais favoráveis às mulheres continuam sendo a de serviços comunitários e sociais onde já estão mais representadas e têm maiores oportunidades de ocuparem cargos de chefia.

Segundo as autoras, em outros setores, como gerências financeiras e comerciais de publicidade, a participação feminina nos cargos de diretoria tem sido expressiva. Outro setor favorável à liderança feminina têm sido as pequenas e microempresas, espaço ocupacional construído também por mulheres. Corsini e Souza Filho (2003) observaram que, nas grandes corporações mundiais, as posições de destaque só começaram a ser ocupadas por mulheres na década de 1990 e apenas 6\% dos cargos têm chefia feminina nas maiores empresas brasileiras.

Segundo Fontenele-Mourão (2006) e Fontenele-Mourão e Galinkin (2007), é na Administração Pública Federal que as mulheres disputam com maior equilíbrio um posto de trabalho, porque o ingresso mediante concurso de provas e títulos evita discriminação na contratação. O grau de escolaridade das mulheres é maior do que o dos homens, mas poucas mulheres disputam cargos gerenciais ou se sentem em condições de assumi-los. Também foi constatada pequena participação de mulheres em cargos elevados na hierarquia das organizações públicas. No serviço público federal, os cargos comissionados, chamados de Designação de Assessoria Superior (DAS), são postos gerenciais considerados de confiança e podem ser ocupados por servidores públicos de carreira da própria organização ou requisitados de outros órgãos, ou até mesmo de organizações privadas.

Afirma Fontenele-Mourão (2006, p. 26) que "o grau de importância e poder do cargo está diretamente relacionado com a gradação do DAS". A autora acrescenta que, quanto maior a responsabilidade no cargo, maior será o nível do DAS, que varia de 1 , o mais baixo, a 6, o mais alto. Os servidores que ocupam cargos de maior responsabilidade são investidos em cargo de comissão de Natureza Especial DAS-6 ou DAS-5 e em cargo de comissão DAS-4. Em 2005, de acordo com dados do Ministério do Planejamento, Orçamento e Gestão, apenas 16,4\% dos 
cargos de DAS-6 e 45,2\% dos DAS-1 eram ocupados por mulheres. O número de mulheres em cargos de alta gerência diminui em proporção inversa ao nível de maior responsabilidade do cargo (Fontenele-Mourão, 2006). Quanto maior o DAS, menor a presença da mulher.

Na Câmara dos Deputados, organização onde a pesquisa foi realizada, a situação é semelhante. Os ocupantes de cargos de confiança de alta chefia são investidos de Funções Comissionadas, FC-10, FC-9, FC-8, FC-7 (a mais alta é a FC-10). São 167 cargos de alta chefia, e, na época da pesquisa, 116 eram ocupados por homens e 51 por mulheres.

\section{A diversidade cultural}

A identidade cultural de um grupo é baseada nas diferenças socioculturais. A cultura grupal distingue os membros de um grupo dos de outro e está relacionada aos indivíduos que compartilham as mesmas normas, os mesmos valores e têm as mesmas prioridades (Cox Jr., 1994). A expressão "estrutura da identidade cultural" é utilizada por Cox Jr. (1994, p. 48) para se referir à configuração particular da cultura grupal. Esta tem dois componentes: o perfil da identidade cultural, referente ao grupo cultural, ou grupos culturais com os quais um indivíduo se identifica; e a força da identidade, referente à importância ou ao valor que o indivíduo dá para a configuração particular da cultura grupal. Os indivíduos têm mais consciência das características de identidade que os diferenciam do grupo majoritário e menos consciência das semelhanças das outras características de identidade (Cox Jr., 1994). Grupos de pessoas num sistema social (países, cidades, organizações, equipes de trabalho) com nítidas diferenças e ligações entre elas compõem a diversidade (Cox Jr., 2001). As ligações podem ser por gênero, nacionalidade, identidade racial, religião, orientação sexual etc.

A diversidade cultural pode ser estudada no nível da sociedade, no organizacional e no grupal e individual. É importante característica da sociedade contemporânea, porque as barreiras físicas entre nações foram reduzidas e a movimentação entre países de trabalhadores de diversas origens geográficas aumentou. A globalização econômica e de mercados aumentou a possibilidade de se trabalhar com grupos mais heterogêneos em termos de raça, gênero e orientação sexual (Hanashiro \& Godoy, 2004). O lócus organizacional passou a abrigar indivíduos de diversas nacionalidades e de culturas diferentes, e a diversidade cultural passou a ser importante característica da força de trabalho. Nesse contexto, percebeu-se que, apesar do aumento do número de mulheres que entram no mercado de trabalho, elas ainda se deparam com diversas formas de discriminação e exclusão: recebem rendimentos menores e têm menos oportunidades de ascensão profissional e de acesso a cargos de alta chefia.

Nas organizações, onde as diferenças de identidade individuais físicas e culturais interagem com complexa gama de fatores individuais, grupais e organizacionais, é necessário prover um ambiente em que todos desenvolvam plenamente seu próprio potencial, em prol do alcance dos objetivos organizacionais (Thomas \& Ely, 1996).

Para Fleury (2000, p. 21),

[...] o objetivo principal da gestão da diversidade cultural é administrar as relações de trabalho, as práticas de emprego e a composição interna da força de trabalho a fim de atrair e reter os melhores talentos dentre os chamados grupos de minoria.

Um dos pontos importantes da diversidade cultural é como trabalhar com regras e normas institucionais que dão origem aos ismos organizacionais, como o heterossexismo (Torres \& Pérez-Nebra, 2004). Mulheres, negros, homossexuais e outros grupos não trazem apenas uma "informação peculiar" (Torres \& Pérez-Nebra, 2004, p. 448), mas também conhecimentos e 
visões diferentes e relevantes competitivamente, sobre como o trabalho pode ser feito, sobre maneiras inovadoras de formular processos, alcançar metas, estruturar tarefas, criar equipes de trabalho efetivas, comunicar ideias e liderar.

Além do ponto de vista organizacional, o debate sobre diversidade também tem sido travado sob a perspectiva de justiça social como elemento de inclusão social. Rezende (2009) faz reflexão sobre o Relatório do Desenvolvimento Humano (RDH), de 2004, segundo o qual a liberdade cultural é elemento essencial para aumento do desenvolvimento humano e social nos próximos anos. E também que os grupos populacionais mais fortemente submetidos a diversas formas de pobreza, desemprego e trabalhos precários são aqueles que "vivenciam alguma situação de submissão, de discriminação e de preconceito, devido ao pertencimento a grupos rotulados como inferiores, menos inteligentes, violentos, incapazes, ignorantes" (Rezende, 2009, p. 160). O RDH também alerta que "o modo como alguns segmentos sociais monopolizam posições de poder garante o afastamento de grupos inteiros da possibilidade de romper com o sofrimento social ao qual estão submetidos cotidianamente" (Rezende, 2009, p. 160). O foco na justiça social e na igualdade pode nortear algumas mudanças nas organizações, de modo a contribuir para inclusão dos grupos de minoria, entre os quais estão as mulheres.

\section{Gênero, feminismo e mudanças no cenário mundial}

Segundo o conceito de Loden e Rosener (1991) sobre diversidade, há duas dimensões da diversidade humana, a primária e a secundária. As dimensões primárias são inerentes ao ser humano desde o nascimento e influenciam os indivíduos durante toda a vida: idade, raça/etnia, habilidades físicas, orientação sexual e gênero. As dimensões secundárias são adquiridas ao longo da vida, podem mudar ou não e são, entre outras: educação, renda, estado civil, crença religiosa, classe social.

Nesta pesquisa, optou-se pelo estudo da dimensão de gênero, que está ligado à construção social de ser homem ou mulher. Sexo é o estado biológico de ser homem ou mulher e gênero são os papéis socioculturais que as pessoas desempenham e os significados culturais atribuídos às diferenças biológicas e sociais. $\mathrm{O}$ objetivo de se distinguir sexo de gênero é diferenciar as características sexuais das características sociais, psíquicas e históricas das pessoas (Izquierdo, 1998).

"Apenas muito recentemente, em nosso meio, os estudos de gênero (ou de relações de gênero) passaram a ocupar algum espaço nas discussões acadêmicas" (Louro, 2004, p. 102). Eles têm origem nos "movimentos sociais de contestação das décadas de 1960 e 1970 e no aumento de estudos acadêmicos sobre a problemática feminina a partir dos anos 1970" (Louro, 2004; Heilborn, 2004). Os movimentos feministas contra a opressão que a mulher sofreu ao longo da história questionaram as diferenças existentes entre mulheres e homens na sociedade ocidental. Durante o século XIX e o fim do século XX, na Grã-Bretanha e nos Estados Unidos, as mulheres lutaram não só pelo direito ao voto, mas também pelo direito à educação, a condições dignas de trabalho, ao exercício da docência, ao poder de decidir o que fazer com o próprio corpo e à sexualidade.

Do início da década de 1960 até o fim dos anos de 1980 as mulheres lutaram pela igualdade e pelo fim da discriminação. Uma das principais características dessa fase foi dar dimensão política a questões tradicionalmente consideradas da esfera privada, como contracepção, aborto, sexualidade e casamento (Bereni, Chauvin, Jaunait \& Revillard, 2008). Para as feministas dessa fase, as instituições sociais perpetuavam as desigualdades de gênero e as diferenças entre mulheres e homens (Fausto-Sterling, 2000). Posteriormente introduziram-se o 
debate queer e o entrelaçamento dos estudos de gênero com outros temas, enfatizando as relações de poder que permeiam sexualidade, classe social, raça, idade etc. (Bereni et al., 2008).

Há uma visão afirmativa do múltiplo, e vários níveis de conhecimento e poder se integram, determinam e influenciam as posições sociais e as oportunidades das mulheres (Styhre \& Eriksson-Zetterquist, 2008). O feminismo causou impacto profundo nas instituições, mas isso não significa que a discriminação, a opressão e o abuso de mulheres e de seus filhos tenham acabado ou tenham sido reduzidos drasticamente (Castells, 1999).

No que se refere à participação das mulheres nos cargos de mando no mundo inteiro, ela era praticamente inexistente até o final dos anos 1970, mas tem aumentado em muitos países, e, em alguns deles, o aumento de gerentes do sexo feminino tem sido significativo (Adler \& Izraeli, 1994). A mudança ocorreu devido a condições econômicas e demográficas favoráveis, políticas públicas de inclusão da mulher e mudanças nos papéis familiares.

As pesquisas sobre o avanço das mulheres em termos de oportunidades de ascensão a postos de alta chefia nas organizações são recentes: primeiramente, nos Estados Unidos, no início da década de 1970; na Europa Ocidental, no início da de 1980; na Ásia, a partir da metade dos anos 1980; e, nos antigos países comunistas do Leste Europeu e na China, no final da década de 1980 (Adler \& Izraeli, 1994). Verificou-se que os movimentos da sociedade levaram à entrada de maior número de mulheres em postos de gerência de níveis mais baixos nas organizações. Entre 1950 e 1970, com a transformação econômica do mundo, antigas economias agrárias tornaram-se economias industrializadas, com geração de demanda de mão de obra barata, e muitas mulheres entraram no mercado de trabalho. Entretanto, os governos não incentivavam a ascensão feminina a cargos de alta chefia. Nos países industrializados e naqueles em processo de industrialização, aumentou o número de bancos e de outros tipos de organizações financeiras, o que abriu oportunidades para as mulheres ocuparem postos de chefia de níveis baixo e médio.

Também no setor público, entre 1970 e 1980 cada vez mais mulheres passaram a ocupar cargos de chefia de níveis inferiores. Novos empregos surgiram, e as mulheres passaram a ocupar cargos de mando. Os homens subiram de nível na hierarquia organizacional, e, com a expansão dos setores público e de serviços, elas começaram a romper a barreira que impedia a ascensão profissional. A competição na economia mundial demandou mais gerentes altamente qualificados, e mulheres qualificadas passaram a ocupar os novos postos de mando das grandes organizações que vêm surgindo em todo o mundo (Adler \& Izraeli, 1994).

À medida que a força de trabalho torna-se cada vez mais diversificada, os cargos de alta chefia das organizações serão ocupados por mão de obra também cada vez mais diversificada. Consequentemente, será imprescindível formular e adotar ações a fim de capacitar os indivíduos pertencentes aos grupos de minorias e as mulheres para assumir os postos de mando. Trata-se de gerenciar a diversidade de modo a obter de força de trabalho heterogênea a mesma produtividade, o mesmo comprometimento, as mesmas qualidades e os mesmos ganhos obtidos de força de trabalho antes em geral homogênea (Thomas Jr., 1994).

\section{Câmara dos Deputados: área administrativa}

Na Câmara dos Deputados, a atividade parlamentar é desenvolvida pelos Deputados Federais, e as atividades administrativas são desempenhadas por 14.697 funcionários (dados obtidos em 3 de maio de 2005). A Câmara dos Deputados recebe pessoas oriundas de diferentes rincões do Brasil e, consequentemente, de raças, religiões e classes sociais diversas, que saem de seus Estados de origem para trabalhar na organização. No entanto, apesar de ter 
um número tão grande de pessoas em seus quadros, na época da pesquisa, não havia qualquer registro na Casa sobre raça, religião, orientação sexual dos servidores ou sobre funcionários com alguma deficiência física. A inexistência de tais dados sugere a pequena importância que a organização tem dado ao gerenciamento da diversidade, de modo a aproveitá-la da melhor maneira possível, em benefício dos servidores, da efetividade da organização e do alcance das metas organizacionais e também em benefício do povo brasileiro, já que a tarefa que os servidores executam dá suporte à atividade parlamentar dos Deputados.

Como representante da sociedade brasileira e com a atribuição de legislar e fiscalizar, a Câmara dos Deputados pode adotar ações para que as mulheres não continuem a se deparar com as diversas formas de discriminação e exclusão a que têm sido submetidas, como rendimentos menores e menos oportunidades de ascensão profissional.

Para contribuir para essa reflexão, esta pesquisa almejou investigar se, pela percepção dos funcionários da Casa, as mulheres e os homens que nela trabalham têm oportunidades iguais de acesso a cargos de alta chefia, com os seguintes objetivos:

Objetivo geral:

- Analisar as oportunidades de ascensão da mulher na carreira, em termos de igualdade na ocupação de cargos de alta chefia na Câmara dos Deputados.

Objetivos específicos:

- Verificar a percepção dos funcionários da Câmara dos Deputados quanto ao exercício por mulheres de cargos de alta chefia na Câmara dos Deputados;

- Descrever como uma amostra de servidores da Câmara dos Deputados percebe as oportunidades de ascensão da mulher na carreira;

- Identificar as diferenças na percepção de servidores do sexo feminino e de servidores do sexo masculino quanto ao exercício por mulheres de cargos de alta chefia na Câmara dos Deputados;

- Identificar as diferenças na percepção de servidoras do sexo feminino ocupantes de cargos de alta chefia e de servidoras do sexo feminino não ocupantes de cargos de alta chefia quanto ao exercício por mulheres de cargos de alta chefia na Câmara dos Deputados.

Para atingir tais objetivos, aplicou-se a Escala de Percepção de Igualdade de Oportunidades entre Mulheres e Homens, desenvolvida e validada por Zauli-Fellows (2006).

\section{Método}

\section{Sujeitos}

A escala foi aplicada entre os servidores do quadro efetivo da Câmara dos Deputados, aqueles que ingressaram na organização por meio de concurso público. Fizeram parte da população deste estudo 3.597 funcionários - 1.955 homens (54,35\%) e 1.642 mulheres $(45,65 \%)$. A opção por servidores do quadro efetivo deveu-se ao fato de todos eles terem ingressado na instituição por meio de concurso público, o que confere igualdade no critério de admissão e na obrigatoriedade de cumprimento do conjunto de atribuições e responsabilidades previstas na estrutura organizacional da Câmara dos Deputados, de acordo com o Regime Jurídico Único (RJU). A limitação a tais servidores é decorrente de possíveis diferenças de percepção entre eles e os demais funcionários, especialmente por se tratar de instituição 
pública, em que há estabilidade no emprego. São todos concursados, com dedicação exclusiva ao trabalho na instituição e, em geral, nela permanecem durante toda a vida profissional.

Após a aplicação e a devolução das escalas, obteve-se a amostra de 1.320 sujeitos. As características da amostra analisada indicaram a maioria de mulheres $(61,9 \%)$. A média geral da idade era de 43,78 anos (desvio padrão $=7,80$ ). A escolaridade geral da amostra era de nível superior completo $(47,7 \%)$. A maioria dos participantes eram pessoas casadas $(60,1 \%)$, que não exerciam cargo de alta chefia $(65,1 \%)$.

\section{Procedimento}

Inicialmente, pediu-se à Diretoria de Recursos Humanos da organização permissão para proceder à coleta de dados, a qual atendeu à solicitação e permitiu o procedimento, feito através do envio de e-mails para todos os servidores, pela rede interna de computadores da organização. A escala foi acessada, respondida e enviada eletronicamente.

Foram definidos com os responsáveis pela rede interna de computadores os critérios de segurança dos dados e as formas de acesso, de forma que todos os respondentes pudessem acessar a escala e, após o preenchimento e a devolução, um segundo acesso fosse bloqueado para o mesmo respondente. Os funcionários receberam o instrumento de pesquisa por meio eletrônico, sem identificação pessoal. O link de acesso à escala foi precedido de mensagem de email enviada a todos eles, assinada pelo Diretor de Recursos Humanos. Na primeira parte da escala de medida, foi apresentada mensagem explicativa da pesquisa e do modo de preenchimento. Para evitar prejudicar os participantes ou expô-los a situações de ridículo, a generalizações, a preconceitos e a discriminação, cuidados foram tomados para preservação dos funcionários, que não foram identificados. As escalas foram enviadas para os servidores no início de novembro. Após um mês, já havia sido obtido o número mínimo necessário para compor a amostra, mas foi enviado outro e-mail de reforço, e a coleta de dados terminou no dia 10 de janeiro de 2006, com 1.320 respondentes.

\section{Instrumento}

A Escala de Percepção de Igualdade de Oportunidades entre Mulheres e Homens consta de questões fechadas, estruturada com escala de concordância do tipo Likert de cinco pontos, variando de 1, "concordo totalmente", a 5, "discordo totalmente". A escala, com 40 itens, continha instruções sobre como responder aos itens, seguidas de duas partes. A primeira, com 34 itens para avaliar a percepção relativa às oportunidades que a mulher têm de ascensão na carreira. A segunda parte continha 6 itens para caracterização demográfica. Procedeu-se a análises de variância ANOVA one-way entre "sexo" e "exercício de cargo de alta chefia" e as médias dos fatores do instrumento. Foram realizadas análises de regressão para investigar se as variáveis independentes "sexo" e "exercício de cargo de alta chefia" eram preditoras da percepção dos servidores da Câmara dos Deputados quanto à igualdade de oportunidades entre mulheres e homens.

\section{Tamanho da amostra e dados omissos}

Em primeiro lugar, fez-se uma análise preliminar dos dados provenientes dos 1.320 sujeitos estabelecidos na amostra, e apenas 7 casos com dados faltantes foram encontrados, todos na seção referente a dados demográficos. Um participante (sujeito n. 1.263) não respondeu a nenhum dado demográfico e foi eliminado das análises. Os outros 6 participantes (sujeitos n. 398, 692, 936, 1.064, 1.234, 1.281) não responderam apenas à variável idade. Nesses casos, o dado omisso foi substituído pela média da idade do grupo. 


\section{Casos extremos entre os sujeitos}

Após usar a medida $\mathrm{D}^{2}$ de Mahalanobis, 54 casos foram excluídos por serem extremos multivariados, que desviavam os dados e não podiam ser analisados com o grupo. Dos 1.320 sujeitos iniciais, permaneceram 1.265 para se proceder às análises fatoriais e de regressão múltipla. Quando comparados com os 1.265 casos escolhidos, o grupo dos casos extremos excluídos da análise apresentava média maior nos itens $2,12,14,15,20,22,23,32,33$ e 34 e menor nos itens $3,5,8,9,10,16$, "idade" e menor número de pessoas solteiras e casadas.

\section{Normalidade e linearidade dos dados}

Os histogramas das variáveis, com as medidas de curtose e de assimetria, e os scatterplots deste estudo foram analisados, e as variáveis estavam de acordo com os parâmetros estabelecidos. Portanto, não foi necessário efetuar qualquer transformação.

Verificados os principais pressupostos para levar a efeito as análises multivariadas, procedeu-se à análise fatorial, para identificar as combinações das variáveis em fatores.

\section{Resultados}

\section{Fatorabilidade da matriz de correlações da escala}

Neste estudo, o KMO foi de 0,86. Pelos resultados obtidos com o teste de esfericidade de Bartlett $\left(\leftrightarrow^{2}=14894,879 ; p \leq 0,001\right)$, a matriz não era de identidade. Os resultados obtidos em termos da fatorabilidade da matriz são observados no Quadro 1.

Quadro 1: Matriz fatorial padrão dos itens da escala $(\mathrm{N}=1.319)$

\begin{tabular}{|c|c|c|c|c|}
\hline Itens & Fator 1 & Fator 2 & Fator 3 & Fator 4 \\
\hline $\begin{array}{l}\text { 25. Em minha organização, até hoje os homens se sentem } \\
\text { constrangidos quando são chefiados por uma mulher. }\end{array}$ & 0,79 & & & \\
\hline $\begin{array}{l}\text { 10. As mulheres sentem que não são aceitas como chefes pelos } \\
\text { homens. }\end{array}$ & 0,78 & & & \\
\hline 12. Os homens não gostam de ser chefiados por mulheres. & 0,75 & & & \\
\hline $\begin{array}{l}\text { 11. Minha organização oferece oportunidades iguais de } \\
\text { capacitação para mulheres e homens. }\end{array}$ & $-0,73$ & & & \\
\hline $\begin{array}{l}\text { 13. Em minha organização, o homem é sempre o escolhido nos } \\
\text { processos de seleção interna para ocupar cargo de alta chefia. }\end{array}$ & 0,73 & & & \\
\hline $\begin{array}{l}\text { 34. Em geral, os homens atribuem o sucesso das mulheres à } \\
\text { sensualidade feminina. }\end{array}$ & 0,61 & & & \\
\hline $\begin{array}{l}\text { 18. Os homens têm mais oportunidades de ascensão na carreira } \\
\text { por causa do preconceito existente contra as mulheres. }\end{array}$ & 0,50 & & & \\
\hline $\begin{array}{l}\text { 7. Em minha organização, é comum as/os funcionárias/os } \\
\text { acharem que os homens têm mais autoridade para gerenciar. }\end{array}$ & 0,46 & & & \\
\hline $\begin{array}{l}\text { 21. Os homens têm dificuldade de lidar com as mulheres como } \\
\text { iguais na atividade profissional. }\end{array}$ & 0,44 & & & \\
\hline $\begin{array}{l}\text { 5. Em minha organização, ninguém deixou de ser escolhido para } \\
\text { ocupar cargo de alta chefia por ser mulher. }\end{array}$ & $-0,41$ & & & \\
\hline $\begin{array}{l}\text { 23. Se houver um cargo vago de alta chefia, as oportunidades de } \\
\text { ele ser ocupado por homens ou mulheres são as mesmas. }\end{array}$ & $-0,41$ & & & \\
\hline
\end{tabular}




\begin{tabular}{|c|c|c|c|c|}
\hline $\begin{array}{l}\text { 14. As mulheres que recorrem ao uso da sedução têm mais } \\
\text { oportunidades de ascensão na carreira. }\end{array}$ & 0,40 & & & \\
\hline $\begin{array}{l}\text { 29. Em minha organização, há retorno da avaliação feita dos } \\
\text { funcionários. }\end{array}$ & & 0,73 & & \\
\hline $\begin{array}{l}\text { 26. Em minha organização, sempre se faz avaliação do } \\
\text { desempenho dos funcionários. }\end{array}$ & & 0,72 & & \\
\hline 27. Em minha organização, as decisões são tomadas em equipe. & & 0,62 & & \\
\hline $\begin{array}{l}\text { 31. Em minha organização, as/os funcionárias/os são treinadas/os } \\
\text { para ter consciência da existência da diversidade de raça, de } \\
\text { gênero, de idade, de religião etc. }\end{array}$ & & 0,60 & & \\
\hline $\begin{array}{l}\text { 30. Em minha organização, investe-se muito no } \\
\text { desenvolvimento profissional dos funcionários. }\end{array}$ & & 0,45 & & \\
\hline $\begin{array}{l}\text { 4. As mulheres têm mais sensibilidade do que os homens para } \\
\text { desempenhar tarefas que envolvem relacionamento interpessoal. }\end{array}$ & & & 0,74 & \\
\hline 32. As mulheres são melhores líderes do que os homens. & & & 0,61 & \\
\hline $\begin{array}{l}\text { 6. O critério de promoção por mérito aumenta as oportunidades } \\
\text { da mulher de ascensão na carreira. }\end{array}$ & & & 0,56 & \\
\hline $\begin{array}{l}\text { 9. Em minha organização, por ter de lutar mais para atingir os } \\
\text { objetivos desejados, as mulheres são mais comprometidas com o } \\
\text { trabalho do que os homens. }\end{array}$ & & & 0,54 & \\
\hline $\begin{array}{l}\text { 15. Em organizações conservadoras, geralmente os cargos de alta } \\
\text { chefia são ocupados por homens. }\end{array}$ & & & 0,49 & \\
\hline $\begin{array}{l}\text { 16. Em minha organização, a maioria dos cargos de alta chefia } \\
\text { são ocupados por homens. }\end{array}$ & & & 0,47 & \\
\hline $\begin{array}{l}\text { 33. As mulheres que desejam ocupar cargos de alta chefia têm de } \\
\text { enfrentar mais desafios do que os homens. }\end{array}$ & & & 0,38 & \\
\hline $\begin{array}{l}\text { 3. Em minha organização, o número de homens que ocupam } \\
\text { cargos de alta chefia é maior por razões culturais. }\end{array}$ & & & 0,37 & \\
\hline $\begin{array}{l}\text { 22. Há carreiras tradicionalmente mais associadas a mulheres do } \\
\text { que a homens, como as de enfermeira, secretária e professora. }\end{array}$ & & & 0,36 & \\
\hline 20. As mulheres têm medo de ocupar cargos de alta chefia. & & & & 0,82 \\
\hline $\begin{array}{l}\text { 8. Mesmo que tenham competência, as mulheres não desejam } \\
\text { ocupar cargos de alta chefia. }\end{array}$ & & & & 0,74 \\
\hline $\begin{array}{l}\text { 2. As mulheres se consideram incapazes de ocupar cargos de alta } \\
\text { chefia. }\end{array}$ & & & & 0,63 \\
\hline $\begin{array}{l}\text { 24. Por serem menos competitivas do que os homens, as } \\
\text { mulheres não se candidatam a processos de seleção interna para } \\
\text { ocupar cargo de alta chefia. }\end{array}$ & & & & 0,58 \\
\hline $\begin{array}{l}\text { 19. Minha organização nada pode fazer para que mulheres e } \\
\text { homens tenham as mesmas oportunidades de ocupar cargo de } \\
\text { alta chefia. }\end{array}$ & & & & 0,41 \\
\hline $\begin{array}{l}\text { 28. As mulheres são emocionalmente menos estáveis do que os } \\
\text { homens. }\end{array}$ & & & & 0,38 \\
\hline $\begin{array}{l}\text { 17. Por achar que não serão escolhidas, as mulheres não se } \\
\text { candidatam a processos de seleção interna para ocupar cargo de } \\
\text { alta chefia. }\end{array}$ & & & & 0,35 \\
\hline Autovalores & 7,48 & 2,90 & 2,39 & 1,94 \\
\hline \% Total de variância explicada & 22,01 & 8,54 & 7,03 & 5,72 \\
\hline Lambda de Guttman & 0,87 & 0,68 & 0,74 & 0,70 \\
\hline Alpha de Cronbach & 0,87 & 0,67 & 0,73 & 0,69 \\
\hline
\end{tabular}

Método de extração: análise dos componentes principais (ACP) e método de rotação promax com normalização Kaiser. 


\section{Interpretação dos fatores}

Após se proceder à análise dos componentes principais com rotação promax, obteve-se estrutura fatorial composta por 33 itens, distribuídos em quatro fatores:

- Fator 1: "percepção do exercício por homens de cargo de alta chefia" (razões da ocupação de cargo de alta chefia por homens).

- Fator 2: "percepção de treinamento e desenvolvimento" (realização de gestão de desempenho dos colaboradores, do trabalho em equipe e crença pela organização no valor do desenvolvimento do colaborador).

- Fator 3: "percepção do exercício por mulheres de cargo de alta chefia" (aspectos positivos do fato de ser mulher, como sensibilidade, capacidade de liderança e comprometimento com o trabalho).

- Fator 4: "percepção do conservadorismo relativo às mulheres" (aspectos negativos do fato de ser mulher e descrença da mulher na respectiva competência).

\section{Diferença entre médias em relação aos fatores da escala}

Para identificar em que medida os participantes do estudo apresentaram respostas significativamente diferentes em relação à "percepção do exercício por homens de cargo de alta chefia", "percepção de treinamento e desenvolvimento", "percepção do exercício por mulheres de cargo de alta chefia" e "percepção do conservadorismo relativo às mulheres", foram realizados testes de comparação de médias. No que diz respeito a sexo, a diferença entre as respostas médias de mulheres e homens foram comparadas por meio da ANOVA, e se observou que houve diferença estatisticamente significativa entre os dois grupos $(p \leq 0,05)$, conforme se vê no Quadro 2.

Quadro 2: Diferença de médias dos Fatores 1, 2, 3 e 4 em relação ao sexo

\begin{tabular}{|c|c|c|c|c|c|c|c|}
\hline \multirow{2}{*}{ Fator } & \multirow{2}{*}{ Sexo } & \multirow{2}{*}{$\mathrm{N}$} & \multirow{2}{*}{ Média } & \multirow{2}{*}{$\begin{array}{l}\text { Desvio } \\
\text { padrão }\end{array}$} & \multicolumn{3}{|c|}{ Estatísticas } \\
\hline & & & & & $\mathrm{F}$ & g. 1. & $\mathrm{p}$ \\
\hline \multirow[t]{2}{*}{ Fator 1} & Masculino & 520 & 2,62 & 0,52 & \multirow[t]{2}{*}{242,24} & \multirow[t]{2}{*}{1318} & \multirow[t]{2}{*}{0,00} \\
\hline & Feminino & 799 & 3,10 & 0,56 & & & \\
\hline \multirow[t]{2}{*}{ Fator 2} & Masculino & 520 & 2,55 & 0,69 & \multirow[t]{2}{*}{10,13} & \multirow[t]{2}{*}{1318} & \multirow[t]{2}{*}{0,00} \\
\hline & Feminino & 799 & 2,43 & 0,63 & & & \\
\hline \multirow[t]{2}{*}{ Fator 3} & Masculino & 520 & 3,12 & 0,51 & \multirow[t]{2}{*}{144,15} & \multirow[t]{2}{*}{1318} & \multirow[t]{2}{*}{0,00} \\
\hline & Feminino & 799 & 3,50 & 0,57 & & & \\
\hline \multirow[t]{2}{*}{ Fator 4} & Masculino & 520 & 2,03 & 0,49 & \multirow[t]{2}{*}{5,70} & \multirow[t]{2}{*}{1318} & \multirow[t]{2}{*}{0,02} \\
\hline & Feminino & 799 & 1,96 & 0,51 & & & \\
\hline
\end{tabular}

Legenda: $\mathrm{F}=$ estatística F; g. l. = grau de liberdade; $p$ = nível de significância.

Em relação ao exercício de cargo de alta chefia, observou-se que houve diferença estatisticamente significativa apenas nos fatores "percepção do exercício por homens de cargo de alta chefia" e "percepção de treinamento e desenvolvimento", como apresentado no Quadro 3. 
Quadro 3: Diferença de médias dos fatores 1, 2, 3 e 4 em relação a cargo

\begin{tabular}{|c|c|c|c|c|c|c|c|}
\hline \multirow[t]{2}{*}{ Fator } & \multirow{2}{*}{$\begin{array}{l}\text { Exercício de } \\
\text { cargo de alta } \\
\text { chefia }\end{array}$} & \multirow[t]{2}{*}{$\mathrm{N}$} & \multirow[t]{2}{*}{ Média } & \multirow{2}{*}{$\begin{array}{l}\text { Desvio } \\
\text { Padrão }\end{array}$} & \multicolumn{3}{|c|}{ Estatísticas } \\
\hline & & & & & $\mathrm{F}$ & g. 1. & $\mathrm{p}$ \\
\hline \multirow{2}{*}{ Fator 1} & Sim & 465 & 2,80 & 0,57 & \multirow[t]{2}{*}{29,03} & \multirow[t]{2}{*}{1318} & \multirow[t]{2}{*}{0,00} \\
\hline & Não & 854 & 2,98 & 0,60 & & & \\
\hline \multirow{2}{*}{ Fator 2} & Sim & 465 & 2,59 & 0,65 & \multirow[t]{2}{*}{19,05} & \multirow[t]{2}{*}{1318} & \multirow[t]{2}{*}{0,00} \\
\hline & Não & 854 & 2,42 & 0,65 & & & \\
\hline \multirow{2}{*}{ Fator 3} & Sim & 465 & 3,32 & 0,55 & \multirow[t]{2}{*}{1,54} & \multirow[t]{2}{*}{1318} & \multirow[t]{2}{*}{0,21} \\
\hline & Não & 854 & 3,36 & 0,60 & & & \\
\hline \multirow{2}{*}{ Fator 4} & Sim & 465 & 1,97 & 0,47 & \multirow[t]{2}{*}{0,99} & \multirow[t]{2}{*}{1318} & \multirow[t]{2}{*}{0,32} \\
\hline & Não & 854 & 2,00 & 0,51 & & & \\
\hline
\end{tabular}

Legenda: $\mathrm{F}=$ estatística F; g. l. = grau de liberdade; $p=$ nível de significância.

Em relação ao nível de função comissionada (FC), os respondentes não apresentaram diferença significativa apenas no fator de "percepção do conservadorismo relativo às mulheres". Os resultados são apresentados no Quadro 4.

Quadro 4: Diferença de médias dos fatores 1, 2, 3 e 4 em relação a função comissionada

\begin{tabular}{|c|c|c|c|c|c|c|c|}
\hline \multirow{2}{*}{ Fator } & \multirow{2}{*}{ Nível de FC } & \multirow{2}{*}{$\mathrm{N}$} & \multirow{2}{*}{ Média } & \multirow{2}{*}{$\begin{array}{l}\text { Desvio } \\
\text { Padrão }\end{array}$} & \multicolumn{3}{|c|}{ Estatísticas } \\
\hline & & & & & $\mathrm{F}$ & g. 1. & $\mathrm{p}$ \\
\hline \multirow{5}{*}{ Fator 1} & FC 4 & 49 & 2,98 & 0,45 & \multirow[t]{5}{*}{4,542977} & \multirow[t]{5}{*}{464} & \multirow[t]{5}{*}{0,001} \\
\hline & FC 5 & 141 & 2,84 & 0,62 & & & \\
\hline & FC 6 & 67 & 2,78 & 0,60 & & & \\
\hline & FC 7 & 182 & 2,77 & 0,52 & & & \\
\hline & FC 8 & 26 & 2,42 & 0,57 & & & \\
\hline \multirow{5}{*}{ Fator 2} & FC 4 & 49 & 2,97 & 0,62 & \multirow[t]{5}{*}{7,339374} & \multirow[t]{5}{*}{464} & \multirow[t]{5}{*}{0,000} \\
\hline & FC 5 & 141 & 2,56 & 0,64 & & & \\
\hline & FC 6 & 67 & 2,54 & 0,67 & & & \\
\hline & FC 7 & 182 & 2,48 & 0,63 & & & \\
\hline & FC 8 & 26 & 2,89 & 0,61 & & & \\
\hline \multirow{5}{*}{ Fator 3} & FC 4 & 49 & 3,56 & 0,42 & \multirow[t]{5}{*}{3,763713} & \multirow[t]{5}{*}{464} & \multirow[t]{5}{*}{0,005} \\
\hline & FC 5 & 141 & 3,31 & 0,59 & & & \\
\hline & FC 6 & 67 & 3,41 & 0,48 & & & \\
\hline & FC 7 & 182 & 3,24 & 0,53 & & & \\
\hline & FC 8 & 26 & 3,26 & 0,65 & & & \\
\hline \multirow{5}{*}{ Fator 4} & FC 4 & 49 & 1,96 & 0,45 & \multirow[t]{5}{*}{1,144184} & \multirow[t]{5}{*}{464} & \multirow[t]{5}{*}{0,335} \\
\hline & FC 5 & 141 & 1,93 & 0,51 & & & \\
\hline & FC 6 & 67 & 1,97 & 0,43 & & & \\
\hline & FC 7 & 182 & 2,02 & 0,47 & & & \\
\hline & FC 8 & 26 & 1,84 & 0,42 & & & \\
\hline
\end{tabular}

Legenda: $\mathrm{F}=$ estatística F; g. 1. = grau de liberdade; $p=$ nível de significância. 
Para o Fator 4, que avalia a percepção do conservadorismo relativo às mulheres, como comentado, não foram observadas diferenças nas médias dos grupos que recebem FC.

\section{Relação entre os fatores da escala}

Para identificar em que medida os fatores da Escala de Percepção de Igualdade de Oportunidades entre Mulheres e Homens sofrem influência das características sociodemográficas dos participantes, foram realizadas análises de regressões lineares múltiplas, nas quais os fatores do instrumento foram inseridos como variáveis critério (VC) e o sexo dos sujeitos e a variável "exercício de cargo de alta chefia" como variáveis antecedentes (VA).

O Fator 1, "percepção do exercício por homens de cargo de alta chefia", apresentou correlação significativa com diversas características demográficas, tais como sexo, estado civil, exercício de cargo de alta chefia e idade. Apenas a variável sexo mostrou elevada magnitude de correlação $(r=0,39 ; p \leq 0,001)$, numa indicação de que ser do sexo feminino ou do sexo masculino é determinante na ideia de que a ocupação de cargo está relacionada a gênero. Ainda quanto ao Fator 1, a correlação mais baixa, porém significativa, foi para o estado civil dos participantes $(r=0,12 ; p \leq 0,001)$, numa demonstração de que é menos determinante para o conceito de tal fator.

No Fator 2, "percepção de treinamento e desenvolvimento", observou-se que a escolaridade e o exercício de cargo de alta chefia apresentaram correlação inversa com tal fator ( $r=-0,12 ; p \leq 0,001$ para ambos).

No Fator 3, "percepção do exercício por mulheres de cargo de alta chefia", percebe-se que houve correlação significativa e positiva com diversas características demográficas (como sexo, estado civil, escolaridade) e relação negativa com idade. Não apresentou, porém, correlação significativa com o exercício de cargo de alta chefia. Observa-se também que a variável sexo apresentou elevada magnitude de correlação $(r=0,31 ; p \leq 0,0001)$, numa indicação de que ser do sexo feminino ou do sexo masculino é determinante na percepção de como as mulheres desempenham um cargo de alta chefia. Verificou-se que a variável idade apresentou correlação inversa com tal fator $(r=-0,08 ; p \leq 0,001)$.

O Fator 4, "percepção do conservadorismo relativo às mulheres", não apresentou correlação significativa com nenhuma característica demográfica, com exceção da variável sexo, que apresenta correlação inversa com esse fator. A categorização para sexo foi feita de tal forma que homens receberam o escore 1 e mulheres receberam o escore 2. A correlação é de baixa magnitude $(r=-0,07 ; p \leq 0,05)$, o que impossibilitou uma interpretação adequada.

\section{Discussão}

Esta pesquisa almejou analisar as oportunidades de ascensão da mulher na carreira, em termos de oportunidades de igualdade na ocupação de cargos de alta chefia na Câmara dos Deputados. Depois de aplicada a Escala de Percepção de Igualdade de Oportunidades entre Mulheres e Homens, observou-se que as mulheres apresentaram maiores médias nos fatores "percepção do exercício por homens de cargo de alta chefia" e de "percepção do exercício por mulheres de cargo de alta chefia", e os homens apresentaram maiores médias nos fatores "percepção de treinamento e desenvolvimento" e "percepção do conservadorismo relativo às mulheres". Tais resultados podem ser indicativos de que as mulheres, mais do que os homens, consideram que a dimensão de gênero tem maior influência nas questões administrativas e 
hierárquicas. Os homens são mais conservadores no que se refere à participação das mulheres em postos de mando na área administrativa, além de atribuir, mais do que elas, maior importância ao oferecimento de treinamento e ao desenvolvimento das habilidades e competências dos servidores.

Aqueles que não ocupam postos de mando apresentaram média maior no fator de "percepção do exercício por homens de cargo de alta chefia", numa indicação de que têm visão mais conservadora do exercício do cargo de alta chefia no que se refere a gênero. E apresentaram média menor no fator de "percepção de treinamento e desenvolvimento", numa indicação de que ser do sexo masculino habilita mais uma pessoa para ser chefe do que treinamento e desenvolvimento.

Nos fatores de "percepção do exercício por mulheres de cargo de alta chefia" e "percepção do conservadorismo relativo às mulheres, não foram observadas diferenças significativas nas médias dos respondentes. Esses dados indicam que para as mulheres é mais intensa do que para os homens a "percepção do exercício por homens de cargo de alta chefia", assim como a "percepção do exercício por mulheres de cargo de alta chefia". Por outro lado, os homens demonstram maior intensidade na "percepção de treinamento e desenvolvimento" dos servidores da Câmara e também na "percepção do conservadorismo relativo às mulheres".

Observa-se que o exercício por homens de cargos de alta chefia é mais percebido pelas não ocupantes de postos de mando. Por isso, talvez se possa deduzir que as não ocupantes consideram que são preteridas na indicação para cargo de alta chefia por ser do sexo feminino, ou seja, por questão de gênero. Por outro lado, o exercício de cargo de alta chefia por mulheres em decorrência da respectiva competência é mais explicitado pelas ocupantes de postos de mando, as quais também têm maior percepção da importância de treinamento e desenvolvimento dos servidores.

Esse resultado indica que quanto menor a escolaridade, maior a média no Fator 2, ou seja, quanto menor o nível de escolaridade do sujeito, maior importância ele atribui a treinamento e desenvolvimento dos servidores. Por outro lado, as pessoas que exercem cargo de alta chefia apresentam maior média no Fator 2, ou seja, atribuem mais importância a treinamento e desenvolvimento dos servidores. Isso significa que quanto menor a idade, maior a média no Fator 3, ou seja, quanto menor a idade do sujeito, maior importância ele atribui a desenvolvimento por mulheres de cargo de alta chefia.

Pode-se concluir que as variáveis "sexo" e "exercício de cargo de alta chefia" têm forte influência nos conceitos relativos ao Fator 1, "percepção do exercício por homens de cargo de alta chefia". O conjunto de variáveis explicou cerca de $2 \%$ da variância total, ou seja, "sexo" e "exercício de cargo de alta chefia" têm influência nos conceitos relativos ao Fator 2, "percepção de treinamento e desenvolvimento". O conjunto de variáveis explicou cerca de $10 \%$ da variância total, numa indicação de que "sexo" e "exercício de cargo de alta chefia" têm forte influência nos conceitos relativos ao Fator 3, "percepção do exercício por mulheres de cargo de alta chefia". "Sexo" e "exercício de cargo de alta chefia" têm alguma influência nos conceitos relativos ao Fator 4, "percepção do conservadorismo relativo às mulheres".

\section{Conclusões}

O Poder Legislativo, símbolo da democracia representativa, é exercido pelo Congresso Nacional, formado pela Câmara dos Deputados e pelo Senado Federal. Composta por 513 Deputados Federais, que representam os diversos segmentos da sociedade brasileira, espera-se que a Casa seja o retrato da democracia, da justiça social e da igualdade. Entretanto, verificou- 
se que, das 799 mulheres que responderam à pesquisa, 50,31\% $(\mathrm{N}=402)$, discordam de que as oportunidades de mulheres ou homens ocuparem um cargo vago de alta chefia são as mesmas. Além de haver maior quantidade de gerentes do sexo masculino nos quadros da organização, é maior a percepção dos servidores de que não há igualdade de oportunidades, principalmente por parte das não ocupantes de posto de mando. Apesar de as mulheres terem conseguido avanços consideráveis no mercado de trabalho e de, segundo Wirth (2001), estarem caminhando rapidamente para romper o teto de vidro, em termos de igualdade de oportunidades, pelo menos na Câmara dos Deputados ele ainda persiste.

Não obstante o feminismo ter causado grande impacto nas instituições, a discriminação, a opressão e o abuso de mulheres e de seus filhos não acabaram, e a desigualdade nas oportunidades na Câmara o confirma. Tanto as mulheres que ocupam cargos de alta chefia quanto as que não os ocupam consideram que o número de homens nos cargos de direção é maior. Isso pode corroborar outra perspectiva dos estudos de gênero, que consiste em apreender as relações sociais entre os sexos como uma relação de poder. Além de dizer que os dois sexos são socialmente diferentes, os estudos de gênero também mostram que as relações são hierarquizadas: em quase todas as sociedades conhecidas, a distribuição de recursos econômicos, políticos e as valorizações simbólicas tendem a ser desiguais, com modalidades e intensidades variadas (Bereni et al., 2008).

Os resultados obtidos propiciaram a compreensão do significado e da importância que a Casa, na pessoa de seus gestores, dá à diversidade. Se quiser adotar política de igualdade de oportunidades entre mulheres e homens, a organização deve implementar a prática da gestão da diversidade cultural, para que servidores e servidoras tomem conhecimento das vantagens de trabalhar num ambiente em que as diferenças são valorizadas e percebam os aspectos positivos do trabalho com grupos de sexo, origem, idade, orientação sexual e raça/etnia diferentes. A falta de conhecimento do tema ficou evidente nas respostas ao item n. 1 da escala, "na Câmara dos Deputados a diversidade de raça, gênero, idade, religião etc. é considerada uma vantagem para o desempenho organizacional", porque a maioria dos respondentes não discordou da afirmação nem concordou com ela.

A organização pode implantar um conjunto de ações relativas à diversidade que se inter-relacionem e se integrem à política de gestão de pessoas. Outros estudos sobre o tema podem ser feitos com o objetivo de enriquecer o entendimento do que representa a diversidade para o indivíduo, para os grupos e para a organização como um todo. Os gerentes da Casa precisam compreender as diferenças culturais, a fim de respeitá-las e de usar, em vez de simplesmente reconhecer, as ideias e habilidades de pessoas que tenham experiências e formações diversas, para aproveitar novas propostas, em vez de simplesmente rejeitá-las de imediato. A Casa, como organização, passará a valorizar a diversidade, que está relacionada com o aumento da efetividade organizacional.

A área de gestão de pessoas pode levar em conta a adoção de estratégias para difundir na organização a importância de ter como gerentes pessoas com as competências, habilidades e atitudes necessárias ao desempenho de determinada função comissionada. Dessa forma, a organização como um todo aos poucos começaria a perceber a importância de o mérito ser levado em consideração na escolha de indivíduos para exercer postos de mando, o que também aumentaria as oportunidades das mulheres de ocupar cargos de alta chefia. A Casa pode implementar a gestão de desempenho, para comparar o desempenho esperado e aquele realmente apresentado no trabalho, a fim de se evitar delegar a alguém tarefa incompatível com a competência individual.

Os responsáveis pela gestão de pessoas podem implementar ações de treinamento, desenvolvimento e educação dos servidores mulheres e homens e intensificar as já implementadas, de modo que sejam superados problemas de desempenho dos indivíduos e eles estejam preparados para novas funções e adaptados a novas tecnologias no trabalho. Mulheres 
e homens agregarão novos conhecimentos, desenvolverão novas habilidades e estarão aptos a assumir novos cargos na Casa. Como instituição imprescindível à democracia, se promover mudanças na política administrativa interna a Câmara dos Deputados pode contribuir para a inclusão daqueles que estão à margem do desenvolvimento, como sugere o Relatório do Desenvolvimento Humano.

Entre as limitações desta pesquisa está a não inclusão de todos os funcionários da organização e os Parlamentares. Não se teve oportunidade de investigar a percepção dos funcionários que trabalham por determinado período de tempo na Câmara dos Deputados. Também não se investigou a percepção dos Deputados, a visão, pelo viés político, da situação das mulheres na área administrativa da Casa. Os Deputados são representantes da sociedade e formuladores das leis que regem a vida da população brasileira, e é da maior importância que tenham conhecimento das diferenças ainda existentes entre a igualdade de oportunidades entre mulheres e homens.

É possível que a pesquisa de campo tenha sido influenciada pelo fenômeno da desejabilidade social, que pode ocorrer quando se investiga algo por meio do uso de questionários, porque os sujeitos tendem a respondê-los da forma que se considera mais aceitável em termos sociais e têm necessidade de obter aprovação ao responder de maneira apropriada (Crowne \& Marlowe, 1960). Portanto, mesmo que o sigilo e a confidencialidade tenham sido garantidos aos participantes desta pesquisa, o fato de a escala ter sido enviada aos servidores da Câmara dos Deputados via e-mail do Diretor de Recursos Humanos da Casa, por meio da rede interna de computadores da organização, pode ter levado algumas pessoas a responder da forma imaginada por elas como a socialmente aceitável.

Os resultados deste estudo podem ser úteis para a Câmara dos Deputados, porque trazem à tona aspectos da cultura organizacional que se refletem na maneira como os servidores percebem a existência ou não da igualdade de oportunidades. Também podem ter utilidade para outras organizações brasileiras, porque os traços da cultura nacional influenciam de alguma forma a cultura organizacional de qualquer ambiente de trabalho e podem representar mais um passo no avanço das investigações sobre as oportunidades que as mulheres têm de ascensão na carreira.

Finalmente, é de se questionar por que a Câmara dos Deputados, instituição do Poder Legislativo que tem como uma de suas funções zelar pela manutenção da democracia no Brasil, não se empenha em ser democrática no sentido da igualdade de oportunidades para todos os servidores da organização, independentemente do sexo.

\section{Referências}

Adler, N. J. \& Izraeli, D. N. (1994). Competitive frontiers: women managers in a global economy. Cambridge, MA: Maxwell.

Bereni, L., Chauvin, S., Jaunait, A. \& Revillard, A. (2008). Introduction aux gender studies: manuel des études sur le genre. Bruxelas: De Boeck.

Castells, M. (1999). O poder da identidade (vol. 2). São Paulo: Paz e Terra.

Coelho, D. (2006). Ascensão profissional de homens e mulheres nas grandes empresas brasileiras. In De Negri, J. A., De Negri, F. \& Coelho, D. (Ed.), Tecnologia, exportação e emprego (pp. 143-159). Brasília, DF: Instituto Econômico de Pesquisa Aplicada.

Corsini, L. F. \& Souza Filho, E. A. (2003). Mulheres no comando e mulheres que são comandadas: um estudo sobre as representações sociais de estilos de liderança e gestão. In Congresso Brasileiro Psicologia: Ciência $\mathfrak{E}$ Profissão. São Paulo: [s. n.].

Cox Jr., T. H. (1994). Cultural diversity in organizations: theory, research and practice. San Francisco, CA: Berrett Koehler.

Cox Jr., T. H. (2001). Creating the multicultural organization: a strategy for capturing the power of diversity. San Francisco, CA: Jossey-Bass. 
Crowne, D. P. \& Marlowe, D. (1960). A new scale of social desirability independent of psychopathology. Journal of Consulting Psychology, 24 (4), 349-354.

Fausto-Sterling, A. (2000). Sexing the body: gender politics and the construction of sexuality. New York: Basic Books.

Fleury, M. T. L. (2000). Gerenciando a diversidade cultural: experiências de empresas brasileiras. Revista de Administração de Empresas, 40 (3), 18-25.

Fontenele-Mourão, T. (2006). Mulheres no topo de carreira: flexibilidade e persistência. Brasília, DF: Secretaria Especial de Políticas para as Mulheres.

Fontenele-Mourão, T. \& Galinkin, A. L. (2007). Gerenciamento feminino: o que pensam as mulheres no topo de carreira? In Reis, A. \& Fontenele-Mourão, T. (Ed.), Trabalho de mulher: riscos, mitos e transformações (pp. 144-155). São Paulo: LTr.

Fontenele-Mourão, T. \& Galinkin, A. L. (2008). Equipes gerenciadas por mulheres: representações sociais sobre o gerenciamento feminino. Psicologia: Reflexão e Crítica, 21 (1), 91-99.

Hanashiro, D. M. M. \& Godoy, A. S. (2004). Um preâmbulo à gestão da diversidade: da teoria à prática. In Anais do XXVIII Encontro Nacional da Associação Nacional dos Programas de Pós-Graduação em Administração. Curitiba: [s. n.].

Heilborn, M. L. (2004). Gênero, identidade sexual e hierarquia. Rio de Janeiro: Garamond.

Instituto Ethos. (2010). Perfil social, racial e de gênero das 500 maiores empresas do Brasil e suas ações afirmativas: pesquisa 2010. São Paulo: Instituto Ethos.

Izquierdo, M. J. (1998). El malestar de la desigualdad. Madrid: Cátedra.

Loden, M. \& Rosener, J. (1991). Workforce America!: managing employee diversity as a vital resource. Homewood, CA: Business One Irwin.

Louro, G. L. (2004). Um corpo estranho: ensaios sobre sexualidade e teoria queer. Belo Horizonte: Autêntica.

Madalozzo, R. (2011). CEOs e composição do conselho de administração: a falta de identificação pode ser motivo para existência de teto de vidro para mulheres no Brasil? Revista de Administração Contemporânea, 15 (1), 126-137.

Rezende, M. J. (2009). Democracia e diversidade cultural: os desafios apontados no Relatório do Desenvolvimento Humano (PNUD/ONU, 2004). Cuadernos Interculturales, 7 (13), 155-179.

Styhre, A. \& Eriksson-Zetterquist, U. (2008). Thinking the multiple in gender and diversity studies: examining the concept of intersectionality. Gender in Management: An International Journal, 23 (8), 567-582.

Thomas, D. A. \& Ely, R. J. (1996). Making differences matter: a new paradigm for managing diversity. Harvard Business Review, 74 (5), 79-90.

Thomas Jr., R. R. (1994). From affirmative action to affirming diversity. Harvard Business Review, 68 (2), 107-118.

Torres, C. V. \& Pérez-Nebra, A. R. (2004). Diversidade cultural no contexto organizacional. In Zanelli, J. C., BorgesAndrade, J. E. \& Bastos, A. V. B. (Ed.), Psicologia, organizações e trabalho no Brasil (pp. 443-463). Porto Alegre: Artmed.

U. S. General Accounting Office. (2002). A new look through the glass ceiling: where are the women? The status of women in management in ten selected industries.

Wirth, L. (2001). Women in management: closer to breaking through the glass ceiling? In Loutfi, M. F. (Ed.), Women, gender and work: what is equality and how do we get there? (pp. 239-249). Genebra, Suíça: International Labour Office.

Zauli-Fellows, A. (2006). Escala de percepção de igualdade de oportunidades entre mulheres e homens. Dissertação de Mestrado, Universidade de Brasília, Brasília, DF.

\section{Endereço para correspondência}

zauliamanda@gmail.com, claudio.v.torres@gmail.com, anagalinkin@uol.com.br 